\title{
Selenium and the immune response
}

\author{
BY R. J. TURNER \\ Department of Biological Sciences, University College of Wales, Aberystwyth SY23 3DA \\ AND JULIE M. FINCH \\ AFRC Institute for Animal Health, Compton, Newbury RG16 ONN
}

Selenium has a long history as a toxicant: the writings of Marco Polo suggest that merchants who ventured into Western China in the late 13 th century to buy rhubarb lost their beasts of burden because seleniferous grasses were used as forage (see Rosenfeld \& Beath, 1964). The element acquired a new reputation from 1957, however, when it was established as an essential micronutrient (Schwarz \& Foltz, 1957) and later as an integral component of glutathione peroxidase (EC 1.11.1.9; GSHPx) (Rotruck et al. 1973). GSHPx, in alliance with vitamin $E$, forms part of the cell's defence against reactive metabolites of oxygen which are produced during the normal operation of a wide spectrum of biological processes; damage to cell membranes and the cytoskeleton will occur if these metabolites are not kept under control (see Nève, 1989). In Se-deficient animals there is a reduction in GSHPx activity accompanied by a variety of cellular malfunctions, including a loss of immunocompetence (for review, see KiremidjianSchumacher \& Stotzky, 1987). The present work will examine the extent and severity of this impairment in single Se $v$. combined Se-vitamin E deficiencies, and develop the idea that measurement of GSHPx activity provides, at best, an incomplete guide to immunological status.

Given that Se has an essential biological role and that local food sources provide very small amounts of it to humans and particularly to livestock in several parts of the world (Gissel-Nielsen et al. 1984), supplementation has become commonplace. Unfortunately, new examples of Se poisoning have emerged, through maladministration of supplements on farms and commercial piggeries. Although these have sometimes arisen from straightforward mistakes in dietary formulation or mixing (e.g. Hill et al. 1985; Hopper et al. 1985), the temptation to oversupplement has been increased by claims in the literature that doses of Se given to laboratory animals in excess of those required for normal growth and development are particularly effective in promoting immune responses and inhibiting cancers. Such claims need to be judged for different species, stages and antigens, and against the low safety margins reported for Se: maximum concentrations tolerated in the animal diet are said to be about twenty to thirty times greater than levels which meet minimum requirements $(0.1 \mu \mathrm{g} / \mathrm{g}$ dry matter (DM); Gissel-Nielsen et al. 1984). The recent poisoning of wildlife on a Californian sanctuary due to an influx of Se-laden water from irrigated farmland (Moore, 1989) has fuelled the debate about acceptable levels of the element.

\section{DEVELOPMENT OF THE ADAPTIVE IMMUNE SYSTEM}

A good starting point for this kind of study is the young chick, since not only are its nutritional requirements well defined, but its $B$ - and T-cell populations responsible respectively for specific antibody- and cell-mediated immunity both develop in discrete 
Table 1. Influence of selenium status on antibody production (antigen $S R B C$ ) compared with Se-vitamin E-adequate controls

\begin{tabular}{|c|c|c|c|c|c|c|}
\hline \multirow[t]{2}{*}{$\begin{array}{l}\text { Dietary } \\
\text { treatment . . }\end{array}$} & \multicolumn{2}{|c|}{ Deficient } & \multicolumn{3}{|c|}{$\begin{array}{c}\text { Supplemented } \\
\text { (dietary Se: } \mu \mathrm{g} / \mathrm{g} \text { ) }\end{array}$} & \multirow[b]{2}{*}{ Reference } \\
\hline & $\mathrm{Se}^{-} \mathrm{E}^{+}$ & $\mathrm{Se}^{--} \mathrm{E}^{-}$ & $\mathrm{Se}^{++}$ & $\mathrm{E}^{+}$ & & \\
\hline Chicks & $\downarrow \rightarrow$ & $\downarrow$ & $\begin{array}{l}1 \\
1\end{array}$ & $\stackrel{\downarrow}{\rightarrow}$ & $\begin{array}{l}\text { (Males) } \\
\text { (Females) }\end{array}$ & Marsh et al. (1981) \\
\hline Mice & $\downarrow$ & $\downarrow \downarrow$ & $\begin{array}{l}1-3 \\
>3\end{array}$ & $\uparrow$ & & $\begin{array}{l}\text { Spallholz (1981a) } \\
\text { Mulhern et al. (1985) }\end{array}$ \\
\hline
\end{tabular}

$\mathrm{Se}^{-}, \mathrm{Se}$ deficient; $\mathrm{Se}^{+}, \mathrm{Se}$ adequate; $\mathrm{Se}^{++}$, supplementary $\mathrm{Se} ; \mathrm{E}^{-}$, vitamin $\mathrm{E}$ deficient; $\mathrm{E}^{+}$, vitamin $\mathrm{E}$ adequate; SRBC, sheep erythrocytes; $\downarrow$, less than controls; $\rightarrow$, not different from controls; $\uparrow$, greater than controls.

primary lymphoid organs, namely the bursa of Fabricius (B) and the thymus (T). Marsh et al. (1986) maintained chicks on diets deficient in Se or vitamin E, or both, from hatching, and examined the organs 1-5 weeks later. Single deficiencies were enough to impair bursal growth (but not overall body-weight), whereas stunting of the thymus was only seen in Se-vitamin E-deficient animals. Similarly, mice with Se deficiency alone did not show impaired thymic growth (Mulhern et al. 1985). On this basis, the B-cell compartment would appear to be more vulnerable to a Se deficiency than T-cells, although this has not been substantiated by functional studies.

In Se-vitamin E-deficient chicks, the thymus and bursa both showed reduced numbers of lymphocytes, preceded by damage to the surrounding epithelia (Marsh et al. 1986). This suggests that the normal flow of inductive signals from epithelial cells to the developing lymphocytes is not occurring. Increased vacuolation of epithelium was also noted in bursal sections from singly-deficient chicks. It would be of interest to determine whether, in the absence of histopathological change or lymphocyte depletion, $\mathrm{Se}$ deficiency on its own exerts more subtle effects on the thymus, especially on the balance of developing T-cell subsets.

\section{ANTIBODY PRODUCTION}

Surprisingly few studies have been made on antibody production in animals with single $v$. combined Se-vitamin E deficiencies and, to the authors' knowledge, no attempts have been made to consider the response to T-dependent $v$. T-independent antigens: sheep erythrocytes (SRBC) figure prominently as the antigen in published work.

Judging by the findings of Marsh et al. (1986) on the susceptibility of the bursa of Fabricius in chicks, we might anticipate an antibody failure in animals with Se deficiency, but other work by the same group (Marsh et al. 1981) has shown that this depends on age: 2-week-old chicks kept on Se- or Se-vitamin E-deficient diets from hatching all showed reduced titres to SRBC, whereas in animals only 1 week older, only the Se-vitamin E-deficient group was disadvantaged (Table 1). Se-deficient mice given $50 \mu \mathrm{g}$ vitamin E/g diet showed reduced IgG but normal IgM responses to SRBC, suggesting that it is the helper T-dependent class switch which is particularly vulnerable to a Se deficiency. If this diet is continued into the second generation however, IgM-producing 
cells too are affected (Mulhern et al. 1985). If weanling mice are maintained on a Se-vitamin E-deficient diet, production of IgM is more rapidly impaired (Spallholz, 1981a).

Early experiments on the immunological effects of Se supplementation (for review, see Spallholz, 1981a) suggested that IgM and IgG antibody responses could be boosted most effectively by concentrations considerably in excess of those required for normal growth, but more recent work has shown that such results depend on species, age, sex and antigen. Dietary Se concentrations which boost anti-SRBC titres in young mice, for example, are inhibitory in male chicks but not females (Table 1); increased antibody titres in young mice and pigs do not occur in older animals (Blodgett et al. 1989); and a dietary supplement of sodium selenite $(1 \mu \mathrm{g} / \mathrm{g})$ which gave the best antibody response to tetanus toxoid in lambs was less effective than a $0.1 \mu \mathrm{g} / \mathrm{g}$ dose in their response to parainfluenza-3 virus and Corynebacterium pseudotuberculosis (Larsen et al. 1988a). Our results have shown that lambs marginally Se deficient and adequate in vitamin $\mathrm{E}$ produced strong antibody responses to a Salmonella dublin vaccine, and that supplementation by injection of barium selenate (which increased blood GSHPx levels five-sevenfold) produced little if any improvement in agglutinin titres (Finch \& Turner, 1986); supplementation may have been more valuable if poor immunogens or suboptimal doses of antigen had been employed. Using a different approach, Arvilommi et al. (1983) obtained a similar result: Finnish men who were marginally Se deficient and adequate in vitamin $E$ showed immunoglobulin levels similar to men receiving a high-Se diet for 11 weeks. This comparison was based on $\operatorname{IgM}, \operatorname{IgG}$ and $\operatorname{IgA}$ taken from the supernatant fractions of blood lymphocytes which had been cultured in the presence of pokeweed mitogen (PWM). Thus, Se did not boost human immunoglobulin production, or any effect was reversed during the $7 \mathrm{~d}$ culture period.

\section{PROLIFERATIVE CAPACITY OF T-AND B-CELLS}

Phytolectins acting as mitogens have been widely used as probes for lymphocyte reactivity. Results of these tests indicate marked differences in susceptibility to Se deficiency among species, although it is not established that the target-cell populations always correspond.

Where Se alone is deficient, responses to the T-cell mitogens concanavalin A. (Con A) or phytohaemagglutinin (PHA), or both, generally become depressed in chicks and single-stomach mammals, but not in ruminants; cells from marginally-Se-deficient humans also maintain their reactivity (Table 2). The poor response in Se-deficient chicks and mice is of interest in view of the reported lack of gross or histopathological change in the thymus gland (see p. 276).

Se-vitamin E-deficient chicks and rats show a more severe depression of T-cell response than Se-deficient animals (Table 2). However, under this regimen (unlike Se deficiency) food intake and weight gain are also decreased. To address this problem, Eskew et al. (1985) pair-fed an additional Se-vitamin E-supplemented group of rats with the Se-vitamin E-deficient group. They concluded that the reduced food intake contributed to the defect in $\mathrm{T}$-cell response, but that the contribution was minor compared with the effect of the Se-vitamin E deficiency.

The B-cell mitogen Escherichia coli lipopolysaccharide (LPS) was also tested in this series of experiments (Eskew et al. 1985). Responses were depressed in the Se-vitamin 
Table 2. Lymphoproliferative responses in selenium $\left(\mathrm{Se}^{-} \mathrm{E}^{+}\right)$and Se-vitamin $\mathrm{E}$ $\left(\mathrm{Se}^{-} \mathrm{E}^{-}\right)$-deficient animals

\begin{tabular}{llcrll}
\hline & & \multicolumn{2}{c}{ Deficiency status } & \\
\cline { 3 - 4 } Species & \multicolumn{1}{c}{ Mitogen } & $\mathrm{Se}^{-} \mathrm{E}^{+}$ & $\mathrm{Se}-\mathrm{E}^{-}$ & \multicolumn{1}{c}{ Reference } \\
\hline Chicks & Con A & $\downarrow$ & $\downarrow \downarrow$ & Marsh et al. (1987) \\
Rats & Con A, PHA & $\downarrow$ & $\downarrow \downarrow$ & Eskew et al. (1985) \\
& LPS & $\downarrow$ & $\downarrow$ & \\
Mice & Con A & $\rightarrow$ & & Parnham et al. (1983) \\
& LPS & $\downarrow$ & & \\
Pigs & PHA & $\downarrow$ & & Larsen \& Tollersrud (1981) \\
Dogs & Con A, PHA, PWM & & $\downarrow$ & Sheffy \& Schultz (1978) \\
Lambs & Con A, PHA, PWM & $\rightarrow$ & $\downarrow$ & Finch \& Turner (1989) \\
Ewes & PHA & & $\rightarrow$ & Turner \& Finch (1990) \\
Calves & PHA & $\rightarrow$ & & Segerson \& Spears (1985) \\
Goats & Con A & $\rightarrow$ & & Aziz \& Klesius (1985) \\
Man & Con A, PHA & $\rightarrow$ & & Arvilommi et al. (1983) \\
\hline \hline
\end{tabular}

Con A, concanavalin A; PHA, phytohaemagglutinin; LPS, lipopolysaccharide; PWM, pokeweed mitogen; $\downarrow$, less than Se-vitamin E-adequate controls; $\rightarrow$, not different from controls.

E-deficient rats, but not in Se-deficient rats. Although Se-deficient mice did show depressed responses to LPS as well as Con A (Parnham et al. 1983), there is, therefore, no evidence as yet in mammals that the B-cell compartment is at greater risk than T-cells.

On the basis of mitogen studies adult ruminants appear to be unusually resistant to the immunological effects of a Se deficiency. Ewes maintained on rations low in both Se (less than $0.04 \mu \mathrm{g} / \mathrm{g} \mathrm{DM}$ ) and vitamin E (less than $10 \mu \mathrm{g} / \mathrm{g} \mathrm{DM}$ ) for 19 weeks always showed good responses to PHA, whilst cells taken from the lambs all showed a decline and eventual failure in T-cell reactivity (Turner \& Finch, 1990). In flocks kept under less severe conditions, where the incidence of lymphocyte failure among lambs was lower, this failure could not be predicted on the basis of their ill thrift or blood GSHPx activity. Whanger et al. (1978) found that rumen microbes from adult sheep had on average a Se concentration forty-six times greater than in the diet on a dry-weight basis; perhaps this microbial Se becomes available to the immunocompetent cells of the host when it acquires ruminant status.

The lymphoproliferative failure described in lambs can be readily and rapidly reversed by injection of sodium selenite in vivo or by adding it to the cells in culture, thus suggesting that the failure resides in the cells' microenvironment rather than the cells themselves (Finch \& Turner, 1989). Lymphocytes from low-Se lambs also react more strongly to phytolectin if they are cultured in the presence of serum or plasma pooled from high-Se rather than low-Se members of the flock (Turner et al. 1985; Finch \& Turner, 1989). The next step should be identification of the immunologically active form(s) of Se in this system: on gel filtration, most of the GSHPx in ovine plasma elutes between the two major protein peaks, but more Se elutes with the first protein peak, possibly as selenoprotein P (Beilstein \& Whanger, 1983; Burk, 1989). 
The amount of Se needed to boost lymphocyte responses of young lambs is low. Cultures showed an enhanced response to PHA when sodium selenite was added in doses of $1 \mathrm{ng} \mathrm{Se} / \mathrm{ml}$ or less, reached a plateau with about $10 \mathrm{ng} / \mathrm{ml}$ and fell dramatically beyond $1 \mu \mathrm{g} / \mathrm{ml}$ (Finch \& Turner, 1989). Sodium selenite or selenomethionine added to the diet at 0.1 or $0.5 \mu \mathrm{g} / \mathrm{g}$ also enhanced responses of older lambs to phytolectins, whilst $1 \mu \mathrm{g} / \mathrm{g}$ was inhibitory (significant for selenomethionine only; Larsen et al. 1988b). Khalil (1989) has recently shown that increased doses of sodium selenite or selenomethionine added to human lymphocytes stimulated with PHA increased the risk of chromosomal aberrations. In cultures containing $6 \mathrm{ng} \mathrm{Se} / \mathrm{ml}$ as selenite, $13 \%$ of cells were aberrant and at $600 \mathrm{ng} / \mathrm{ml}$ the value rose to $40 \%$; cultures containing corresponding concentrations of $\mathrm{Se}$ as selenomethionine had half the aberrations.

Se appears to cause less genetic damage to rodents at sub-lethal doses (see Khalit, 1989). Moreover, proliferative responses to PHA and to alloantigens were more than doubled in mice given excess dietary Se $(2 \mu \mathrm{g} / \mathrm{g})$ compared with Se-adequate mice (Kiremidjian-Schumacher et al. 1990). Output of interleukin-2 (1L-2) by murine T-helper cells was not influenced by dietary intake of Se; instead the authors suggest that the micronutrient affects proliferation by modulating the expression of IL-2 receptors on the lymphocyte surface.

\section{ANTI-TUMOUR RESPONSES}

Epidemiological studies which show an inverse relationship between cancer incidence and Se status in humans may not be as valid as generally supposed, since the high intake of Se-rich plant foods could alter nutritional status in other ways (Flodin, 1988). The anti-cancer effects seen in laboratory animals have been achieved with Se in nutritional excess, sometimes at near-toxic levels (where GSHPx activity is unlikely to be a critical factor); and evidence that the Se is acting by inhibiting the proliferation of cancer cells has been difficult to reconcile with reports of an enhancement of anti-cancer immune responses by Se excess, bearing in mind the importance of clonal expansion in the generation of immunocompetent cells.

Attempts to clarify the role of the immune system in this context have emphasized the differential effects of Se on key defensive components. Kay et al. (1986) reported that addition of Se in amounts that inhibited proliferation of human lymphocytes and cultured tumour cell lines did not inhibit the activity of natural killer (NK) cells (up to $400 \mathrm{ng} \mathrm{Se} / \mathrm{ml}$ ). On the other hand, stimulation or maintenance of NK activity under conditions of Se excess will be of little benefit against NK-resistant tumours, especially where (as in rats) other potential anti-tumour defences such as T-cell-mediated responses and antibody production are concurrently inhibited (Koller et al. 1986). Petrie et al. (1989) have recently argued that impairment of T-lymphocyte activity is also selective, suppressor function being more vulnerable to Se excess than delivery of help or cytotoxic responses; nevertheless, the balance between enhancement and inhibition of antitumour responses by a given dose of Se would appear to be a delicate one, given the heterogeneity of tumour cells.

Fewer experiments have attempted to demonstrate that susceptibility to cancers is increased in Se-deficient animals. However, mice kept on diets low in Se or vitamin E, or both, showed reduced NK and T-cell-mediated cytotoxic activity (Meeker et al. 1985; Roy et al. 1990). In vitro tests for antibody-dependent cell-mediated cytotoxicity 
Table 3. Phagocyte activity in selenium-deficient rats*

\begin{tabular}{|c|c|c|}
\hline Dietary treatment ... & $\mathrm{Se}^{-} \mathrm{E}^{+}$ & $\mathrm{Se}^{-} \mathrm{E}^{-}$ \\
\hline \multicolumn{3}{|l|}{ Neutrophils } \\
\hline Chemotaxis & $\downarrow$ & \\
\hline Random migration & $\rightarrow$ & \\
\hline Microbial ingestion & $\rightarrow$ & \\
\hline Candidacidal activity & $\downarrow$ & \\
\hline Bactericidal activity & $\rightarrow$ & \\
\hline \multicolumn{3}{|l|}{ Macrophages } \\
\hline Candidacidal activity & $\downarrow$ & $\downarrow$ \\
\hline Bactericidal activity & $\rightarrow$ & $\rightarrow$ \\
\hline Antibody-dependent cytolysis & $\rightarrow$ & $\rightarrow$ \\
\hline Regulation of T-cell blastogenesis & $\rightarrow$ & $\rightarrow$ \\
\hline Release of arachidonic acid metabolites & $\uparrow ?$ & $\uparrow$ \\
\hline
\end{tabular}

$\mathrm{Se}^{-} \mathrm{E}^{+}$, Se deficient vitamin $\mathrm{E}$ adequate; $\mathrm{Se}^{-} \mathrm{E}^{-}, \mathrm{Se}$-vitamin $\mathrm{E}$ deficient; $\downarrow$, less than $\mathrm{Se}$-vitamin $\mathrm{E}$ adequate controls; $\rightarrow$, not different from controls; $\uparrow$, greater than controls.

* From Boyne et al. (1986), Kiremidjian-Schumacher \& Stotzky (1987) and Eskew et al. (1989).

(ADCC) by Meeker et al. 1985 (using a standard antibody preparation) showed no effect of a deficiency, although this may not hold in vivo where antibody production has been impaired.

\section{PHAGOCYTE FUNCTIONS}

Production of reactive oxygen species by phagocytes contributes to their anti-microbial activity, and failure to detoxify these products when they leak from phagolysosomes into the surrounding cytoplasm could damage the rest of the cell's microbicidal and metabolic functions. Neutrophils and macrophages from animals with a single Se deficiency show low GSHPx activity and a failure to kill ingested Candida yeasts; bacterial killing, on the other hand, can remain unimpaired even in animals that are $\mathrm{Se}$ and vitamin $\mathrm{E}$ deficient (Table 3). Microbicidal defects seen in animals with Se deficiency are not associated with reduced uptake of particles or a failure to opsonize them (Boyne \& Arthur, 1986), but this is perhaps more likely in Se and vitamin E-deficient animals (Turner \& Finch, 1990). The functional properties of neutrophils from low-Se donors can be restored or stimulated by incubation with small doses of sodium selenite $(20-200 \mathrm{ng} \mathrm{Se} / \mathrm{ml})$ for $1 \mathrm{~h}$ or less (Aziz et al. 1984; Dimitrov et al. 1984; Urban \& Jarstrand, 1986).

Unlike neutrophils, the influence of Se on eosinophil activity has received little, if any, attention. This is surprising in view of their role in allergic responses and in parasite infections. Macrophages also deserve more attention with respect to their regulatory functions. Reports so far indicate that changes in the proliferative capacity of rodent lymphocytes according to Se status are not due to an altered ability of macrophages to produce interleukin-1 (IL-1) or to present antigen (Eskew et al. 1985; Koller et al. 1986; Kiremidjian-Schumacher et al. 1990). However, altered secretion of arachidonic acid metabolites such as $\mathrm{PGE}_{2}$ by macrophages could have important regulatory implications (Eskew et al. 1989). 


\section{RESISTANCE TO INFECTIONS}

Given the complexity of the immune system in vivo, coupled with pressures of cost and public opinion, it is not surprising that the use of in vitro measures of immunocompetence of the kind described in the present paper has increased in recent years. Such tests should, in principle, facilitate predictions about the kinds of defence which might be compromised or boosted by a change of Se status in vivo. An in vitro failure in the T-cell compartment, for example, could suggest increased susceptibility to viral or mycobacterial infections; a decline in B-cell function could jeopardize responses against other bacteria. Moreover, a failure or boosting effect occurring in vitro could be reinforced in vivo, since there is close interaction and interdependence among immunocompetent cells.

Arguments such as these have failed to convince several investigators, who see an over-reliance on in vitro tests or rodent models, or both, and a poor correlation with studies of host resistance to infection in animals or humans of differing Se status under 'field' conditions (Van Vleet \& Watson, 1984; Murray \& Murray, 1985; Suttle \& Jones, 1989).

The most obvious dangers lie in cross-species comparisons. It is becoming increasingly clear that sheep, humans and mice, for example, do not all respond to Se deficiency or excess in the same way as each other, nor will responses be as reproducible where genotype, environment and diet are varied. Deficiencies achieved with semi-synthetic diets in experimental rodents and chicks are likely to be more uniform and severe than with natural diets received by humans or farm animals, whilst caging and penning produce their own stresses on the immune system (e.g. Phillippo et al. 1987). There is also a frequent failure to control or report vitamin $E$ status in studies on Se. This is regrettable, since there is now ample evidence that adequate levels of the former moderate immunological effects of the latter (Tables 1 and 2).

Our recent studies on lambs (Finch \& Turner, 1989) have shown good agreement in the response of lymphocytes to phytolectins after in vitro $v$. in vivo supplementation of Se. However, a change of Se status in vivo could affect a whole spectrum of non-immune as well as immune mechanisms which alter the balance between the host and a living parasite, and which cannot be predicted accurately by the use of probes such as phytolectins, SRBC antigens or dead vaccines. DeWitt (1957) reported that Se-vitamin E-deficient mice harboured $69 \%$ more Schistosoma mansoni worms than mice on an adequate diet following exposure to a standard number of cercariae, but the worms were severely stunted and most failed to reach sexual maturity. A similar point is made in Table 4: Se-deficient rodents show increased susceptibility to some pathogens, but in other cases deficiency harms the pathogen more than the host, perhaps by reducing its ability to replicate, or by making target host cell environments less attractive to it. An immunological explanation for the differences shown in Table 4 seems unlikely since it would require a selective improvement in immune responses under deficiency conditions.

For future work, it is our view that laboratory tests should focus on the location and form of immunologically active Se in the body. Infections of concern in the field are commonly those of the respiratory and intestinal tracts, yet laboratory assessments of humans and domestic animals rely heavily on blood samples. Paynter's (1979) work on sheep showed a higher GSHPx activity in the lymphoid tissues examined (spleen and lymph nodes) than all other tissues except the blood after Se supplementation, and a 
Table 4. Effects of selenium deficiency on survival of experimentally infected rodents*

\begin{tabular}{|c|c|c|}
\hline Rodent & Pathogen & $\begin{array}{c}\text { Host } \\
\text { survival rate }\end{array}$ \\
\hline $\begin{array}{l}\mathrm{M} \\
\mathrm{M} \\
\mathrm{R}\end{array}$ & $\begin{array}{l}\text { Diplococcus pneumoniae Type } 1 \\
\text { Candida albicans } \\
\text { Staphylococcus aureus }\end{array}$ & $\downarrow$ \\
\hline $\begin{array}{l}\mathrm{R} \\
\mathrm{M} \\
\mathrm{M} \\
\mathrm{M}\end{array}$ & $\begin{array}{l}\text { Salmonella typhimurium } \\
\text { Plasmodium berghei } \\
\text { Listeria monocytogenes } \\
\text { Pseudorabies virus }\end{array}$ & $\uparrow$ \\
\hline $\mathbf{M}$ & Streptococcus, Gp A, Type 50 & $\rightarrow$ \\
\hline
\end{tabular}

M, mice; $R$, rats; $\downarrow$, less than Se-adequate controls; $\rightarrow$, not different from controls; $\uparrow$, greater than controls.

* From Spallholz (1981b), Boyne et al. (1984, 1986), Murray \& Murray (1985) and Boyne \& Arthur (1986).

much smaller reduction in this activity compared with the blood in Se-deficient animals. This suggests a priority of Se supply to lymphoid tissues. Assessments of immunocompetence in Se-deficient animals based on whole blood or RBC GSHPx activity and functional tests of blood leucocytes could, therefore, be misleadingly low. GSHPx measurements themselves could be another red herring: GSHPx activity in sheep plasma is less than $1 \%$ of whole-blood activity (Paynter, 1979) and, as we have suggested previously other selenoproteins exist in the plasma which deserve fuller investigation of their immunological activity. Studies on rats (Behne \& Wolters, 1983; Behne \& Hofer-Bosse, 1984) have shown that in the thymus and spleen, as in the plasma, Se is mainly present in forms other than GSHPx, and under deficiency conditions the Se in the body gets redistributed to these selenoproteins at the expense of GSHPx. Moreover, when Se-deficient rats are repleted by injection of radiolabelled sodium selenite, certain organs including the spleen and thymus take up a disproportionate share. These authors also note that vitamin E-deficient rats had about $20 \%$ less Se in their plasma than vitamin E-adequate rats given the same amount of dietary Se.

Current laboratory tests of immunocompetence in rodents of differing Se status do not escape criticism because here the spleen, being large and convenient, is the organ of choice for study, whilst the relatively inaccessible lymphoid tissues associated with the gut (GALT) and bronchi which provide important local immunity to mucosal surfaces have been neglected. It is tempting to speculate that there is a priority of Se supply not only to the immune system but also within it. No sound evidence exists as yet to support this, but it is worth noting that deterioration in immune function due to age, which may occur partly through oxidative damage, is seen less in GALT than in other compartments of the immune system (Szewczuk et al. 1981).

Despite the fact that current laboratory tests of immunocompetence provide, at best, only a rough guide to the likely outcome of an infection, expectations based on in vitro tests have occasionally been fulfilled in vivo (e.g. Boyne \& Arthur, 1986; Boyne et al. 1986). In conclusion, good correlations are possible, if the choice of in vitro test is appropriate, i.e. it tests a key protective arm of the immune system appropriate to a particular disease, and if in vivo tests (both in the laboratory and field) are properly controlled with respect to age, sex, housing, Se and vitamin E status. 


\section{REFERENCES}

Arvilommi, H., Poikonen, K., Jokinen, I., Muukkonen, O., Rasanen, L., Foreman, J. \& Huttunen, J. K. (1983). Selenium and immune functions in humans. Infection and Immunity 41, 185-189.

Aziz, E. S. \& Klesius, P. H. (1985). The effect of selenium deficiency in goats on lymphocyte production of leukocyte migration inhibitory factor. Veterinary Immunology and Immunopathology 10, 381-390.

Aziz, E. S., Klesius, P. H. \& Frandsen, J. C. (1984). Effects of selenium on polymorphonuclear leukocyte function in goats. American Journal of Veterinary Research 45, 1715-1718.

Behne, D. \& Höfer-Bosse, T. (1984). Effects of a low selenium status on the distribution and retention of selenium in the rat. Journal of Nutrition 114, 1289-1296.

Behne, D. \& Wolters, W. (1983). Distribution of selenium and glutathione peroxidase in the rat. Journal of Nutrition 113, 456-461.

Beilstein, M. A. \& Whanger, P. D. (1983). Distribution of selenium and glutathione peroxidase in blood fractions from humans, rhesus and squirrel monkeys, rats and sheep. Journal of Nutrition 113, 2138-2146.

Blodgett, D. J., Schurig, G. G., Kornegay, E. T., Meldrum, J. B. \& Bonnette, E. D. (1989). Failure of an enhanced dietary selenium concentration to stimulate humoral immunity in gestating swine. Nutrition Reports International 40, 543-550.

Boyne, R. \& Arthur, J. R. (1986). The response of selenium-deficient mice to Candida albicans infection. Journal of Nutrition 116, 816-822.

Boyne, R., Arthur, J. R. \& Wilson, A. B. (1986). An in vivo and in vitro study of selenium deficiency and infection in rats. Journal of Comparative Pathology 96, 379-386.

Boyne, R., Mann, S. O. \& Arthur, J. R. (1984). Effect of Salmonella typhimurium infection on selenium deficient rats. Microbios Letters 27, 83-87.

Burk, R. F. (1989). Newer roles of selenium in nutrition. Journal of Nutrition 119, 1051-1054.

DeWitt, W. B. (1957). Experimental schistosomiasis mansoni in mice maintained on nutritionally deficient diets. 2. Survival and development of Schistosoma mansoni in mice maintained on Torula yeast diet deficient in Factor 3, vitamin E, and cystine. Journal of Parasitology 43, 129-135.

Dimitrov, N. V., Meyer, C., Ullrey, D. E., Ku, P. K., Primack, S. \& Miller, E. R. (1984). Selenium as a metabolic modulator of phagocytosis. In Selenium in Biology and Medicine, pp. 254-262 [J. E. Spallholz, J. L. Martin and H. E. Ganther, editors]. New York: Avi Publishing Co.

Eskew, M. L., Scholz, R. W., Reddy, C. C., Todhunter, D. A. \& Zarkower, A. (1985). Effects of vitamin E and selenium deficiencies on rat immune function. Immunology 54, 173-180.

Eskew, M. L., Zarkower, A., Scheuchenzuber, W. J., Burgess, J. R., Scholz, R. W., Hildenbrandt, G. \& Reddy, C. C. (1989). Effects of inadequate vitamin $E$ and/or selenium nutrition on the release of arachidonic acid metabolites in rat alveolar macrophages. Prostaglandins 38, 79-89.

Finch, J. M. \& Turner, R. J, (1986). Selenium supplementation in lambs: effects on antibody responses to a Salmonella vaccine. Veterinary Record 119, 430-431.

Finch, J. M. \& Turner, R. J. (1989). Enhancement of ovine lymphocyte responses: a comparison of selenium and vitamin E supplementation. Veterinary Immunology and Immunopathology 23, 245-256.

Flodin, N. W. (1988). Pharmacology of Micronutrients. Current Topics in Nutrition and Disease, vol. 20 , pp. 269-284. New York: A. R. Liss Inc.

Gissel-Nielsen, G., Gupta, U. C., Lamand, M. \& Westermarck, T. (1984). Selenium in soils and plants and its importance in livestock and human nutrition. Advances in Agronomy 37, 397-460.

Hill, J., Allison, F. \& Halpin, C. (1985). An episode of acute selenium toxicity in a commercial piggery. Australian Veterinary Journal 62, 207-209.

Hopper, S. A., Greig, A. \& McMurray, C. H. (1985). Selenium poisoning in lambs. Veterinary Record 116, 569-571.

Kay, H. D., Petrie, H. T. \& Klassen, L. W. (1986). In vitro effects of selenium and T-cell growth factor (TCGF) on natural killer (NK) cell function of lymphocytes from human peripheral blood. IRCS Medical Science 14, 691-692.

Khalil, A. M. (1989). The induction of chromosome aberrations in human purified peripheral blood lymphocytes following in vitro exposure to selenium. Mutation Research 224, 503-506.

Kiremidjian-Schumacher, L., Roy, M., Wishe, H. I., Cohen, M. W. \& Stotzky, G. (1990). Selenium and immune cell functions. 1. Effect on lymphocyte proliferation and production of interleukin 1 and interleukin 2. Proceedings of the Society for Experimental Biology and Medicine 193, 136-142.

Kiremidjian-Schumacher, L. \& Stotzky, G. (1987). Selenium and immune responses. Environmental Research 42, 277-303. 
Koller, L. D., Exon, J. H., Talcott, P. A., Osborne, C. A. \& Henningsen, G. M. (1986). Immune responses in rats supplemented with selenium. Clinical and Experimental Immunology 63, 570-576.

Larsen, H. J., Moksnes, K. \& Overnes, G. (1988a). Influence of selenium on antibody production in sheep. Research in Veterinary Science 45, 4-10.

Larsen, H. J., Overnes, G. \& Moksnes, K. (1988b). Effect of selenium on sheep lymphocyte responses to mitogens. Research in Veterinary Science 45, 11-15.

Larsen, H. J. \& Tollersrud, S. (1981). Effect of dietary vitamin E and selenium on the phytohaemagglutinin response of pig lymphocytes. Research in Veterinary Science 31, 301-305.

Marsh, J. A., Combs, G. F., Whitacre, M. E. \& Dietert, R. R. (1986). Effect of selenium and vitamin E dietary deficiencies on chick lymphoid organ development. Proceedings of the Society for Experimental Biology and Medicine 182, 425-436.

Marsh, J. A., Dietert, R. R. \& Combs, G. F. (1981). Influence of dietary selenium and vitamin E on the humoral immunity of the chick. Proceedings of the Society for Experimental Biology and Medicine 166, 228-236.

Marsh, J. A., Dietert, R. R. \& Combs, G. F. (1987). Effect of dietary selenium and vitamin E deficiencies in the chicken on Con A-induced splenocyte proliferation. Progress in Clinical and Biological Research 238, 333-345.

Meeker, H. C., Eskew, M. L., Scheuchenzuber, W., Scholz, R. W. \& Zarkower, A. (1985). Anti oxidant effects on cell-mediated immunity. Journal of Leukocyte Biology 38, 451-458.

Moore, S. B. (1989). Selenium in agricultural drainage: essential nutrient or toxic threat? Journal of Irrigation and Drainage Engineering 115, 21-28.

Mulhern, S. A., Taylor, G. L., Magruder, L. E. \& Vessey, A. R. (1985). Deficient levels of dietary selenium suppress the antibody response in first and second generation mice. Nutrition Research 5, 201-210.

Murray, J. M. \& Murray, A. B. (1985). The effects of selenium deficiency and repletion on host resistance to infection. In Trace Elements in Man and Animals. TEMA-5, pp. 244-247. Cambridge: Commonwealth Agricultural Bureau.

Nève, J. (1989). Biological functions of selenium. In Selenium in Medicine and Biology, pp. 97-111 [J. Nève and A. Favier, editors]. New York: Walter de Gruyter.

Parnham, M. J., Winkelmann, J. \& Leyck, S. (1983). Macrophage, lymphocyte and chronic inflammatory responses in selenium deficient rodents. Association with decreased glutathione peroxidase activity. International Journal of Immunopharmacology 5, 455-461.

Paynter, D. I. (1979). Glutathione peroxidase and selenium in sheep. 1. Effect of intraruminal selenium pellets on tissue glutathione peroxidase activities. Australian Journal of Agricultural Research 30, 695-702.

Petrie, H. T., Klassen, L. W. \& Kay, H. D. (1989). Selenium and the immune response. 1. Modulation of alloreactive human lymphocyte functions in vitro. Journal of Leukocyte Biology 45, 207-214.

Phillippo, M., Arthur, J. R., Price, J. \& Halliday, G. J. (1987). The effects of selenium, housing and management on the incidence of pneumonia in housed calves. Veterinary Record 121, 509-512.

Rosenfeld, I. \& Beath, O. A. (1964). Selenium: Geobotany, Biochemistry, Toxicity and Nutrition. New York: Academic Press.

Rotruck, J. T., Pope, A. L., Ganther, H. E., Swanson, A. B., Hafeman, D. G. \& Hoekstra, W. G. (1973). Selenium: biochemical role as a component of glutathione peroxidase. Science 179, 588-590.

Roy, M., Kiremidjian-Schumacher, L., Wishe, H. I., Cohen, M. W. \& Stotzky, G. (1990). Selenium and immune cell functions. 2. Effect on lymphocyte-mediated cytotoxicity. Proceedings of the Society for Experimental Biology and Medicine 193, 143-148.

Schwarz, K. \& Foltz, C. M. (1957). Selenium as an integral part of Factor 3 against dietary necrotic liver degeneration. Journal of American Chemical Society 79, 3292-3293.

Segerson, E. C. \& Spears, J. W. (1985). Selenium status and phytohaemagglutinin-stimulated T lymphocytes from beef calves. Biological Trace Element Research 8, 173-180.

Sheffy, B. E. \& Schultz, R. D. (1978). Nutrition and the immune response. Cornell Veterinarian 68, Suppl. 7, 48-61.

Spallholz, J. E. (1981a). Anti-inflammatory, immunologic and carcinostatic attributes of selenium in experimental animals. In Diet and Resistance to Disease. Advances in Experimental Medicine and Biology, vol. 135, pp. 43-62 [M. Phillips and A. Baetz, editors]. New York: Plenum.

Spallholz, J. E. (1981b). Selenium. What role in immunity and immune cytotoxicity? In Selenium in Biology and Medicine, pp. 103-117 [J. E. Spallholz, J. L. Martin and H. E. Ganther, editors]. Connecticut: Avi Publishing Co. 
Suttle, N. F. \& Jones, D. G. (1989). Trace elements, disease resistance and immune responsiveness in ruminants. Journal of Nutrition 119, 1055-1061.

Szewczuk, M. R., Campbell, R. J. \& Jung, L. K. (1981). Lack of age-associated immune dysfunction in mucosa-associated lymph nodes. Journal of Immunology 126, 2200-2204.

Turner, R. J. \& Finch, J. M. (1990). Immunological malfunctions associated with low selenium-vitamin E diets in lambs. Journal of Comparative Pathology 102, 99-109.

Turner, R. J., Wheatley, L. E. \& Beck, N. F. G. (1985). Stimulatory effects of selenium on mitogen responses in lambs. Veterinary Immunology and Immunopathology 8, 119-124.

Urban, T. \& Jarstrand, C. (1986). Selenium effects on human neutrophilic granulocyte function in vitro. Immunopharmacology 12, 167-172.

Van Vleet, J. F. \& Watson, R. R. (1984). Effects of selenium and vitamin E on resistance to infectious disease In Nutrition, Disease Resistance and Immune Function. Clinical and Experimental Nutrition, vol. 1, pp. 299-312 [R. R. Watson, editor]. New York: Marcel Dekker.

Whanger, P. D., Weswig, P. H. \& Oldfield, J. E. (1978). Selenium, sulfur and nitrogen levels in ovine rumen microorganisms. Journal of Animal Science 46, 515-519. 